\title{
Evaluation of Left Ventricular Ejection Fraction as a Measure of Pump Performance in Patients With Chronic Mitral Regurgitation
}

\author{
Steven B.H. Timmis, ${ }^{*}$ MD, Marvin M. Kirsh, MD, Daniel G. Montgomery, and \\ Mark R. Starling, MD

\begin{abstract}
Left ventricular (LV) ejection fraction may not adequately detect a reduction in LV systolic performance resulting from chronic mitral regurgitation (MR), due to ventricular unloading into the low-impedance left atrium. To determine whether LV ejection fraction sufficiently gauges myocardial function in MR, nine patients were studied using micromanometer-measured LV pressures and biplane cineventriculography before and 1 year after mitral valve surgery. Six control patients were also studied. LV ejection fraction was normal in MR patients, despite an increase in LV end-systolic volume index. LV endsystolic pressure-volume and stress-volume ratios in MR patients were lower than in controls $(P<0.05$ and $P<0.01)$, suggesting that LV systolic performance fell. One year after mitral valve surgery, LV ejection fraction decreased $(P<0.05)$ even though LV end-systolic volume index $(P<0.05)$, pressure-volume $(P<0.05)$, and stress-volume ratios $(P<0.01)$ all improved. Thus, $L V$ ejection fraction inadequately reflected LV systolic function in MR patients before and after mitral valve surgery. Cathet. Cardiovasc. Intervent. 49:290-296, 2000.
\end{abstract}

Key words: ventricular function; myocardial contraction; left ventricular hypertrophy

\section{INTRODUCTION}

Chronic mitral regurgitation (MR) causes progressive left ventricular (LV) systolic dysfunction. If LV dysfunction is advanced, mitral valve surgery may worsen pump function, leading to congestive heart failure [1,2]. To anticipate postsurgical deterioration in LV pump function and subsequent cardiac decompensation, an accurate preoperative assessment of LV myocardial performance is essential. Mitral valve surgery should be performed when there is early LV systolic impairment. In clinical practice, LV ejection fraction (EF) is the measure of pump performance most frequently used to guide the timing of surgery [1,3-6] Indeed, LV EF is useful to predict postoperative outcomes when the preoperative value is elevated or reduced. However, LV EF is insensitive in predicting postoperative LV systolic function when the preoperative value is in the normal range [7]. Unloading of the left ventricle into the low impedance left atrium may normalize the preoperative LV EF, even after a cardiomyopathic process develops [1]. Nevertheless, the inference that LV EF is an insufficient measure of LV pump or myocardial function in MR patients has never been directly and systematically evaluated. The present investigation compares LV EF to more loadindependent indexes of LV systolic performance and intrinsic myocardial contractility to determine whether
EF adequately gauges LV pump function in chronic MR both before and after mitral valve surgery.

\section{MATERIALS AND METHODS}

\section{Patients}

The study population consisted of nine male patients with chronic MR, referred for cardiac catheterization to assess the hemodynamic significance of their valvular heart disease. All patients had angiographically severe, $4+$ MR. They were compared to six male control pa-

University of Michigan and Veterans Affairs Medical Centers, Ann Arbor, Michigan

Presented in part at the American Heart Association Annual Sessions, 1994, Dallas, TX.

Grant sponsor: the National Heart, Lung, and Blood Institute; Grant number: R01-HL36450; Grant sponsor: the Kughn Clinical Research Center, National Institutes of Health, Bethesda, Maryland; Grant number: M01-RR00042; Grant sponsor: Department of Veterans Affairs, Washington, D.C.

*Correspondence to: Dr. Steven B.H. Timmis, Division of Cardiology, 7th Floor, William Beaumont Hospital, 3601 West Thirteen Mile Road, Royal Oak, MI 48073. E-mail: stimmis@beaumont.edu

Received 12 May 1999; Revision accepted 22 August 1999 
tients, referred for angiographic evaluation of atypical chest pain, in whom no cardiac disease was demonstrated. Each of the patients in both groups were in normal sinus rhythm. None of them had angiographic evidence of obstructive coronary artery disease.

Nitrates were discontinued at least $12 \mathrm{hr}$ prior to the cardiac catheterization. Beta-adrenergic and calciumchannel blockers, as well as other vasoactive medications were stopped at least $24 \mathrm{hr}$ prior to cardiac catheterization. All patients gave written informed consent on forms approved by the Human Studies Committees at the University of Michigan or the Veterans Affairs Medical Centers, Ann Arbor, Michigan.

\section{Protocol}

After intracardiac pressures, cardiac output, and normal coronary arteries were documented by diagnostic right and left heart catheterization, patients were entered into the study. The protocol consisted of obtaining simultaneous micromanometer-measured LV pressures and biplane cineventriculography. The nine patients with chronic MR underwent mitral valve surgery on the basis of clinical and cardiac catheterization data. The decision to do mitral valve surgery was not influenced by the study data. Each of the nine patients had a follow-up cardiac catheterization approximately 12 months after their mitral valve surgery.

\section{Hemodynamics}

After completion of the cardiac catheterization, a micromanometer-tipped catheter (Millar Instruments, Houston, TX) was positioned to measure LV pressures during biplane cineventriculography. Hemodynamic recordings included an electrocardiogram along with micromanometer-measured LV pressures $(200 \mathrm{~mm} \mathrm{Hg}$ scale). These measurements were obtained simultaneously with biplane cineventriculography. Pressure waveforms were hand-digitized using a Calcomp 9100 inductance digitizing surface beginning at the peak of the $\mathrm{R}$-wave of the simultaneously recorded ECG [8]. Interpolation of the LV pressure data was performed to guarantee isochronicity of the LV pressure values with the middle of each cineventriculographic frame pair.

\section{Biplane Cineventriculography}

Biplane cineventriculography was performed in the $30^{\circ}$ right anterior oblique and $60^{\circ}$ left anterior oblique projections after injection of 36 to $48 \mathrm{ml}$ of Renographin-76 at 60 frames/sec. One of the first three beats after contrast injection that did not follow a ventricular ectopic beat was used for volume analysis [9]. Left ventricular volumes were calculated frame by frame using a sonic digitizer (Science Accessories) mounted on a Vanguard XR-35 cine projector. The long axes were measured in both projections from the apex to the junction of the aortic and mitral valve planes. With these long axes and the digitized silhouettes, a modified Simpson's rule algorithm was used to calculate LV volumes [10].

Midwall circumferential stress $\left(s_{\theta}\right)$ was used to quantitate the integrated contribution of LV pressure, chamber geometry, and wall thickness to myocardial fiber loading. Left ventricular end-diastolic wall thickness was determined from the digitized average dimension between the epicardial and endocardial surfaces of the LV anterior free wall over the middle one-third of the long axis in the $30^{\circ}$ right anterior oblique projection [8]. Left ventricular mass was calculated by subtracting the LV chamber volume from the combined LV chamber and myocardial volume, then multiplying by the specific gravity (1.015) of myocardium [11]. Frame-by-frame estimates of LV wall thickness were obtained using the iterative approach of Hugenholtz et al. [12]. With the corresponding digitized LV pressures, long axes, minor dimensions, and wall thickness values, frame-by-frame midwall circumferential stresses were calculated using the following equation [13],

$$
\boldsymbol{\varsigma}_{\theta}=(P b / h)\left(1-h / 2 b-b_{2} / 2 a_{2}\right),
$$

for a thick-walled ellipsoid of revolution. In this equation, $P$ is the instantaneous LV pressure, $h$ is the estimated LV wall thickness, and $a$ and $b$ are the midwall semimajor and semiminor axes, respectively.

\section{Assessment of Left Ventricular Pump Performance}

To assess LV pump performance, corresponding micromanometer LV pressures and cineventriculographic volumes were plotted to generate pressure-volume loops. The circumferential stress and cineventriculographic data were also combined to produce stress-volume loops. From these loops, end-diastolic volume was measured at the maximal ventricular volume after atrial contraction. The LV end-diastolic pressure and stress were identified at the Z-point, occurring on the LV pressure waveform just prior to the initial systolic deflection. To calculate LV EF, end-systole was determined as the minimal ventricular volume. Left ventricular EF was determined by subtracting the minimal LV volume from the end-diastolic volume, dividing by the end-diastolic volume, then multiplying by 100 . For all other measures of LV pump performance, end-systolic volume, pressure, and stress were defined as occurring at the maximal pressure-volume ratio on the pressure-volume loop. Finally, LV endsystolic pressure-volume and stress-volume ratios were derived. These two values were used as relatively loadindependent indexes of LV pump performance [14]. 
TABLE I. Hemodynamic Data

\begin{tabular}{|c|c|c|c|}
\hline & $\begin{array}{l}\text { Control } \\
(\mathrm{n}=6)\end{array}$ & $\begin{array}{l}\mathrm{MR}_{\text {pre }} \\
(\mathrm{n}=9)\end{array}$ & $\begin{array}{l}\mathrm{MR}_{\text {post }} \\
(\mathrm{n}=9)\end{array}$ \\
\hline Heart rate $(\mathrm{BPM})$ & $71 \pm 6$ & $80 \pm 11$ & $79 \pm 8$ \\
\hline Body surface area $\left(\mathrm{m}^{2}\right)$ & $1.82 \pm 0.13$ & $1.90 \pm 0.15$ & $1.88 \pm 0.17$ \\
\hline LV mass $(\mathrm{gm})$ & $173 \pm 60$ & $228 \pm 41$ & $178 \pm 42$ \\
\hline End-diastolic volume (ml) & $183 \pm 65$ & $290 \pm 76^{\mathrm{a}}$ & $188 \pm 48^{c}$ \\
\hline End-systolic volume (ml) & $80 \pm 21$ & $113 \pm 48$ & $86 \pm 31^{\mathrm{c}}$ \\
\hline $\begin{array}{l}\text { End-diastolic volume index } \\
\qquad\left(\mathrm{ml} / \mathrm{m}^{2}\right)\end{array}$ & $100 \pm 31$ & $153 \pm 46^{\mathrm{a}}$ & $101 \pm 29^{\mathrm{e}}$ \\
\hline $\begin{array}{l}\text { End-systolic volume index } \\
\qquad\left(\mathrm{ml} / \mathrm{m}^{2}\right)\end{array}$ & $44 \pm 11$ & $60 \pm 30$ & $47 \pm 19^{c}$ \\
\hline End-diastolic stress $\left(\mathrm{gm} / \mathrm{cm}^{2}\right)$ & $31 \pm 17$ & $41 \pm 17$ & $33 \pm 15$ \\
\hline End-systolic stress $\left(\mathrm{gm} / \mathrm{cm}^{2}\right)$ & $184 \pm 38$ & $161 \pm 65$ & $177 \pm 37$ \\
\hline Ejection fraction $(\%)$ & $61 \pm 3$ & $61 \pm 9$ & $54 \pm 9^{c}$ \\
\hline $\begin{array}{l}\text { End-systolic pressure-volume } \\
\text { ratio }(\mathrm{mm} \mathrm{Hg} / \mathrm{ml})\end{array}$ & $1.56 \pm 0.52$ & $0.96 \pm 0.36^{\mathrm{a}}$ & $1.40 \pm 0.57^{\mathrm{c}}$ \\
\hline $\begin{array}{l}\text { End-systolic stress-volume } \\
\text { ratio }\left(\mathrm{gm} / \mathrm{cm}^{2} / \mathrm{ml}\right)\end{array}$ & $2.34 \pm 0.75$ & $1.37 \pm 0.39^{\mathrm{b}}$ & $2.13 \pm 0.78^{\mathrm{d}}$ \\
\hline Nakano's $\mathrm{K}_{\mathrm{sm}}$ & $4.57 \pm 2.63$ & $5.33 \pm 1.07$ & $5.42 \pm 1.24$ \\
\hline
\end{tabular}

${ }^{\mathrm{a}} P<0.05 \mathrm{MR}_{\text {pre }}$ vs. control.

${ }^{\mathrm{b}} P<0.01 \mathrm{MR}_{\text {pre }}$ vs. control.

${ }^{\mathrm{c}} P<0.05 \mathrm{MR}_{\text {post }}$ vs. $\mathrm{MR}_{\text {pre }}$

${ }^{\mathrm{d}} P<0.01 \mathrm{MR}_{\text {post }}$ vs. $\mathrm{MR}_{\text {pre }}$.

${ }^{\mathrm{e}} P<0.001 \mathrm{MR}_{\text {post }}$ vs. $\mathrm{MR}_{\text {pre }}$

\section{Assessment of Left Ventricular Contractile State}

An index of LV systolic myocardial stiffness, based on the LV midwall stress-strain relation, was used to assess LV contractility $[15,16]$. This model of stiffness incorporates LV size, shape, mass, wall thickness, and chamber pressure to generate a value of stiffness, the $\mathrm{K}_{\mathrm{sm}}$. The $\mathrm{K}_{\mathrm{sm}}$ varies directly with myocardial stiffness and hence contractility. This stiffness value has been shown to correlate with variations in contractility, not only in normal ventricles [15] but also in hearts with chronic MR [16].

\section{Statistical Analysis}

Comparisons between control and study patients were made using unpaired Student's $t$-tests. Paired Student's $t$-tests were used to compare MR patients before and after mitral valve surgery. Analysis of variance was applied when appropriate. Results are presented as the mean \pm 1 standard deviation.

\section{RESULTS}

Hemodynamic data are presented in Table I and Figures 1-6 for the six control subjects and nine MR patients both before $\left(\mathrm{MR}_{\text {pre }}\right)$ and after $\left(\mathrm{MR}_{\text {post }}\right)$ mitral valve surgery. Figure 1 demonstrates that the LV end-diastolic volume index was significantly higher in chronic MR patients before surgery than in control subjects $(P=$ $0.03)$. The LV end-systolic volume index also tended to
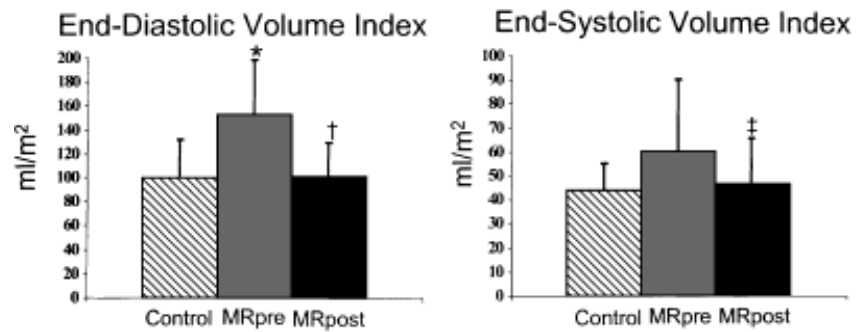

Fig. 1. Volume overload in patients with chronic mitral regurgitation $\left(\mathrm{MR}_{\mathrm{pre}}\right)$ is demonstrated by the increase in end-diastolic and end-systolic volume indexes compared to control. End-diastolic and end-systolic volume indexes return to normal following mitral valve surgery $\left(\mathrm{MR}_{\text {post }}\right)$. Asterisk, $P<0.05 \mathrm{MR}_{\mathrm{pre}}$ vs. control. Cross, $P<0.01 \mathrm{MR}_{\text {post }}$ Vs. $\mathrm{MR}_{\text {pre }}$. Double-cross, $P<$ $0.05 \mathrm{MR}_{\text {post }}$ vs. $\mathrm{MR}_{\text {pre}}$.

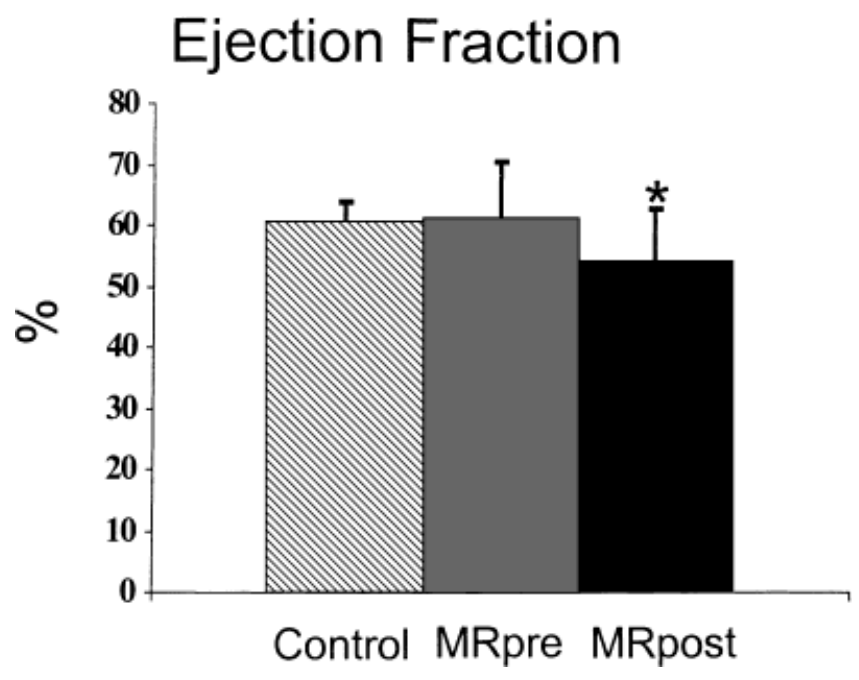

Fig. 2. Compared to control, ejection fraction is unaffected by chronic mitral regurgitation $\left(\mathrm{MR}_{\mathrm{pre}}\right.$ ). Following mitral valve surgery ( MR $_{\text {post }}$ ), however, ejection fraction worsens. Asterisk, $P<$ $0.05 \mathrm{MR}_{\text {post }}$ vs. $M R_{\text {pre }}$.

be higher presurgical MR patients, but did not achieve statistical significance $(P=0.23)$. Meanwhile, LV EF was not affected by chronic MR, with similar values seen in preoperative MR patients and control subjects $(P=$ 0.90 ; Fig. 2). One year after mitral valve surgery, the mean LV end-diastolic and end-systolic volume indexes improved toward normal in MR subjects $(P=0.001$ and $P=0.018$, respectively; Fig. 1). However, LV EF significantly worsened postoperatively in MR patients, as shown in Figure $2(P<0.05)$.

The LV end-diastolic and end-systolic stress were unaffected by chronic MR (Fig. 3). Despite the increase in LV end-diastolic volume index in presurgical MR patients, their LV end-diastolic stress did not differ from control subjects $(P=0.30)$. Likewise, the increase in LV end-systolic volume index in preoperative MR patients 

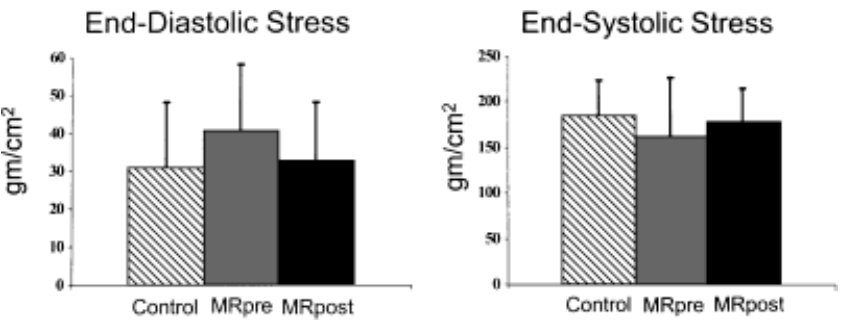

Fig. 3. End-diastolic and end-systolic stresses are not influenced by chronic mitral regurgitation ( $\mathrm{MR}_{\mathrm{pre}}$ ) compared to control. Likewise, wall stresses are not affected by the surgical correction of mitral regurgitation ( $\mathbf{M R}_{\text {post }}$ ).

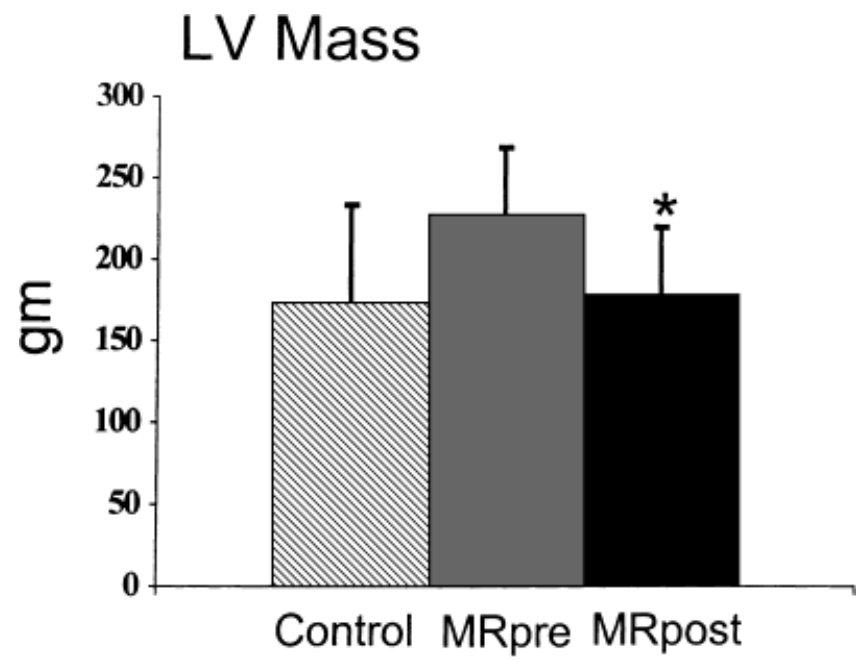

Fig. 4. Left ventricular hypertrophy seen in patients with chronic mitral regurgitation $\left(\mathrm{MR}_{\text {pre}}\right)$ regresses following mitral valve surgery ( $\mathbf{M R}_{\text {post }}$ ) toward normal control values. Asterisk, $P<0.05 M_{\text {pre }}$ Vs. MR post

did not lead to a significant change in LV end-systolic stress compared to control subjects $(P=0.45)$. Although LV end-diastolic volume index fell in MR patients after surgery, LV end-diastolic stress remained unchanged $\left(P=\mathrm{NS}\right.$ compared to control and to $\left.\mathrm{MR}_{\mathrm{pre}}\right)$. Similarly, LV end-systolic stress did not change in MR patients following surgery $(P=\mathrm{NS}$ compared to control and to $\mathrm{MR}_{\text {pre }}$ ), despite a reduction in LV end-systolic volume index.

Figure 4 illustrates that LV mass was also affected by chronic MR. Patients with MR had greater LV mass compared to control subjects $(P=0.054)$. After mitral valve surgery, LV hypertrophy regressed in MR patients toward normal $(P=0.86$ vs. control, $P=0.003$ vs. $\left.\mathrm{MR}_{\text {pre }}\right)$, resulting from more favorable loading conditions.

The recovery of LV pump function following mitral valve surgery is demonstrated in Figure 5, which highlights the changes in the LV end-systolic pressure-vol-
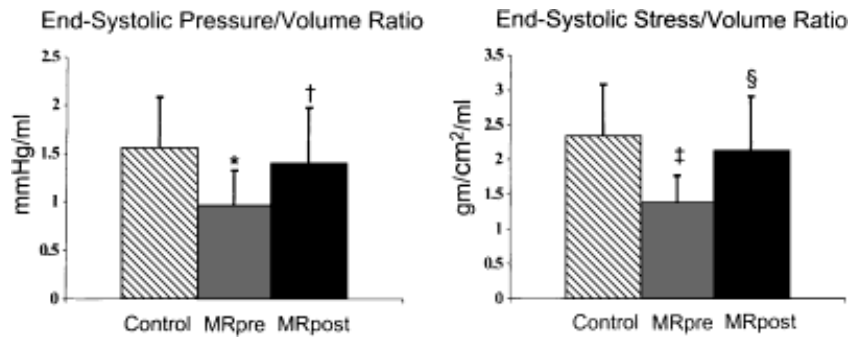

Fig. 5. Depressed left ventricular pump function is illustrated by decreased end-systolic pressure-volume and stress-volume ratios in patients with chronic mitral regurgitation $\left(\mathrm{MR}_{\text {pre }}\right)$. Improvement in left ventricular performance following mitral valve surgery ( $\mathrm{MR}_{\text {post }}$ ) is shown by the increase in the value of both ratios toward normal. Asterisk, $P<0.05 \mathrm{MR}_{\text {pre }}$ vs. control.

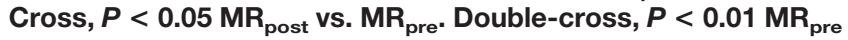
vs. control. Double-S, $P<0.01 \mathrm{MR}_{\text {post }}$ vs. $\mathrm{MR}_{\mathrm{pre}}$.

\section{Nakano's $\mathrm{K}_{\mathrm{sm}}$}

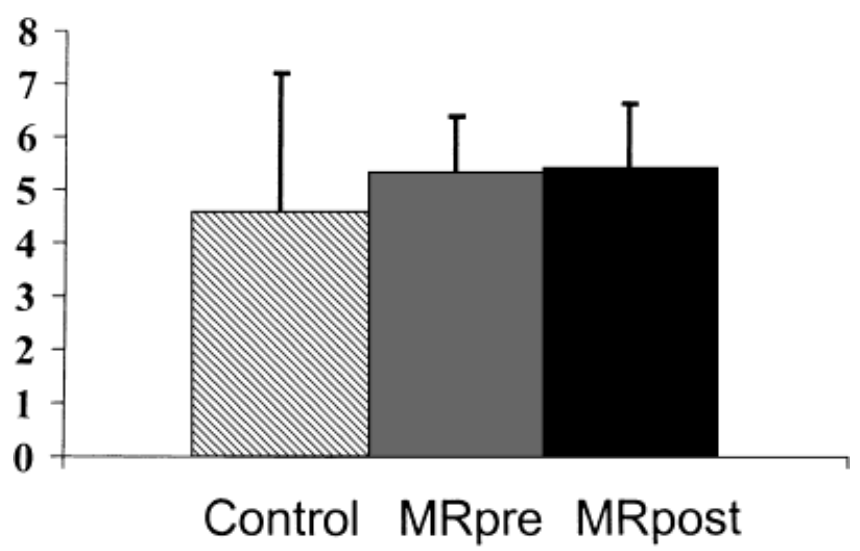

Fig. 6. The Nakano model $\left(\mathrm{K}_{\mathrm{sm}}\right)$ of left ventricular systolic myocardial stiffness remained normal in chronic mitral regurgitation patients before $\left(\mathrm{MR}_{\text {pre }}\right)$ and after $\left(\mathrm{MR}_{\text {post }}\right)$ mitral valve surgery compared to control subjects.

ume and stress-volume ratios. Prior to surgery, the LV end-systolic pressure-volume ratio was significantly depressed in MR patients compared to control subjects $(P$ $=0.02)$. The LV end-systolic stress-volume ratio was also significantly depressed in MR patients compared to control subjects $(P=0.006)$. After surgery, however, MR patients experience an increase in the LV end-systolic pressure-volume ratio toward normal ( $P=0.59$ vs. control, $P=0.03$ vs. $\left.\mathrm{MR}_{\text {pre }}\right)$. The LV end-systolic stressvolume ratio showed a similar increase in MR patients following surgery ( $P=0.61$ vs. control, $P=0.008$ vs. $\left.\mathrm{MR}_{\text {pre }}\right)$. The improvement in LV end-systolic pressurevolume and stress-volume ratios following surgery reflected a recovery in LV pump performance. Thus, while LV ejection fraction fell in MR patients following mitral valve surgery, LV pump performance improved. 
Finally, the effect of MR on LV systolic myocardial stiffness is shown in Figure 6. The Nakano model of LV stiffness revealed no difference between presurgical MR patients and control subjects $(P=0.44)$. After surgical correction of MR, stiffness remained unchanged $(P=$ 0.86 vs. $\mathrm{MR}_{\mathrm{pre}}, P=0.41$ vs. control). Thus, myocardial contractility was unaffected by MR or surgery in this cohort of patients.

\section{DISCUSSION}

These data suggest that LV pump performance is depressed in chronic MR patients and improves following mitral valve surgery. Postsurgical improvement in LV pump function is demonstrated by the reduction in LV end-systolic volume index, while LV end-systolic stress remained unchanged. Thus, the LV generated a smaller systolic volume after surgery, despite the lack of change in end-systolic stress. This improvement in LV pump performance is more clearly shown by the rise in LV end-systolic pressure-volume and stress-volume ratios in MR patients following mitral valve surgery. Meanwhile, intrinsic myocardial contractility, represented by the Nakano model of systolic myocardial stiffness, was unaffected in MR patients before and after valve surgery.

Although LV end-systolic parameters demonstrated systolic LV dysfunction in chronic MR patients, LV EF was normal. Furthermore, while postsurgical LV endsystolic indexes of pump performance improved and contractility remained unchanged, LV EF worsened. While LV EF can be negatively affected by changes in afterload, the LV end-systolic wall stress was similar in chronic MR subjects before and after surgery. Consequently, LV EF inadequately reflected LV pump performance in chronic MR patients both prior to and following successful mitral valve surgery.

\section{Left Ventricular Volumes and Stresses}

Left ventricular end-diastolic volume index was elevated in chronic MR patients, while LV end-diastolic stress remained normal. These changes confirm that volume overload is characteristic of chronic MR. Attempts to use preoperative $\mathrm{LV}$ end-diastolic volume index or end-diastolic dimension in MR to predict LV pump performance or clinical prognosis after mitral valve surgery have had limited success [17-19]. Rather, these LV enddiastolic parameters simply reflect the primary adaptive change in chronic MR that helps maintain LV EF.

On the other hand, LV end-systolic volume index and end-systolic dimension have been more successful in assessing ventricular function in MR patients. Their values may vary inversely with LV systolic performance and are minimally affected by preload [14]. The elevated LV end-systolic volume index seen in our study patients before mitral valve surgery, accompanied by a normal LV end-systolic stress, most likely represents a reduction in LV pump function. In the meantime, LV EF was normal. A number of investigators have shown that an elevated preoperative LV end-systolic volume index in chronic MR patients undergoing valve surgery correlates with a poor postoperative LV EF [18] or clinical outcome [17,20-22]. Other studies have demonstrated that LV end-systolic dimension, determined echocardiographically, is able to predict prognosis after surgery [19,22,23-26].

After surgery, the LV end-systolic volume index decreased toward normal in our patients, while end-systolic stress remained stable. These findings suggest that LV pump performance improved, producing smaller postsurgical LV end-systolic volumes while carrying the same end-systolic stress as before surgery. However, LV EF worsened, incorrectly suggesting that LV pump function deteriorated.

\section{Left Ventricular Mass}

The influence of chronic MR and its surgical repair on LV mass was also studied. Patients with chronic MR possessed greater LV mass than the control subjects, a finding consistent with other studies [19,24,27]. Following mitral valve surgery, however, LV hypertrophy significantly regressed. Two separate studies have shown that a fall in LV mass is seen in MR patients who experience clinical improvement after mitral valve surgery $[19,24]$. Recognizing LV hypertrophy preoperatively does not necessarily predict clinical outcome following surgical correction of chronic MR. However, regression of LV hypertrophy supports the conclusion that LV pump performance improved.

\section{End-Systolic Pressure-Volume and Stress-Volume Ratios}

Increased afterload may result in higher LV end-systolic volumes and mass. To account for afterload, LV end-systolic pressure-volume and stress-volume ratios were used. These ratios incorporate LV pressure and stress into their values. When the LV generates a smaller volume at any given level of pressure or stress, an increase in the LV end-systolic pressure-volume and stress-volume ratios will occur. This change represents an improvement in the LV pump performance [14]. Furthermore, the end-systolic nature of these parameters reduces the influence of LV end-diastolic volume, pressure, and stress. In our patients, preoperative LV endsystolic pressure-volume and stress-volume ratios were depressed compared to control subjects. After mitral valve surgery, LV pump performance improved with significant increases in both ratios toward control. Carabello et al. [17] used end-systolic pressure-volume and 
stress-volume ratios to predict clinical improvement in MR patients undergoing mitral valve surgery. Nakazawa et al. [28] also showed that preoperative LV end-systolic stress-volume ratios were useful in predicting clinical outcome following mitral surgery.

\section{Systolic Myocardial Stiffness}

The Nakano model of stiffness has been shown to represent the myocardial stress-strain relationship, which varies directly with contractility [15]. Stiffness incorporates the variables of LV size, shape, wall thickness, and mass into LV circumferential wall stress in order to reflect myocardial fiber load. It then relates these variables to fiber shortening. Therefore, stiffness provides more specific information about the contractile state than any other parameter used in this investigation. Nakano et al. [16] has shown that stiffness, and therefore contractility, is depressed in canines with surgically induced MR. Our chronic MR patients did not show a change in stiffness before or after mitral valve surgery. The lack of LV contractile dysfunction in our patients is probably due to early evaluation and treatment of MR, before significant changes in stiffness could be detected. Nevertheless, these data demonstrate that a change in contractility did not contribute to the decline in $\mathrm{LV}$ EF observed following mitral valve surgery.

\section{Study Limitations}

There are two potential limitations to our investigation. First, the complexity of the study, its invasive nature, and the paucity of patients with isolated mitral regurgitation limited the number of study subjects. Second, we did not control for the type of mitral valve surgery performed. The objective of the study was to examine the value of following LV EF in chronic MR patients as an assessment of LV pump function, not to test the merits of different surgical modalities. Moreover, the small size of the study group precluded a meaningful comparison of outcome between replacement versus repair.

\section{CONCLUSIONS}

Patients with chronic MR demonstrated an elevated LV end-systolic volume index and a depressed LV endsystolic pressure-volume and stress-volume ratio, reflecting LV pump dysfunction. However, LV EF was normal. Following mitral valve surgery, LV end-systolic volume index decreased toward normal. Likewise, LV end-systolic pressure-volume and stress-volume ratios significantly improved. Recovery in LV pump performance was further supported by regression of LV hypertrophy after surgery. Meanwhile, contractility remained normal. Despite these findings, LV ejection fraction fell after surgical correction of chronic MR. Although a high or low preoperative LV EF is still useful to predict clinical and hemodynamic outcomes after mitral valve surgery, a normal preoperative LV EF is less reliable in assessing postoperative results [7]. Most patients considering mitral valve surgery, including those in the current study, fall into this latter group. Our observations suggest that in this cohort of chronic MR patients, LV EF does not adequately represent LV pump performance or myocardial contractility prior to or following mitral valve surgery. Whether the LV end-systolic parameters evaluated in the present investigation are superior to $\mathrm{LV}$ EF in predicting postoperative clinical outcomes, such as symptoms and survival, requires a larger scale investigation.

\section{REFERENCES}

1. Ross J. Left ventricular function and the timing of surgical treatment in valvular heart disease. Ann Intern Med 1981;94:498-504.

2. Wong CYH, Spotnitz HM. Systolic and diastolic properties of the human left ventricle during valve replacement for chronic mitral regurgitation. Am J Cardiol 1981;47:40-50.

3. Acar J, Michel PL, Luxereau P, Vahanian A, Cormier B. Indications for surgery in mitral regurgitation. Eur Heart J 1991; 12(Suppl B):52-54.

4. Hochreiter C, Niles N, Devereux R, Kligfield P, Borer J. Mitral regurgitation: relationship of noninvasive descriptors of right and left ventricular performance to clinical and hemodynamic findings and to prognosis in medically and surgically treated patients. Circulation 1986;73:900-912.

5. Phillips HR, Levine FH, Carter JE, Boucher CA, Osbakken MD, Okada RD. Mitral valve replacement for isolated mitral regurgitation: analysis of clinical course and late postoperative left ventricular ejection fraction. Am J Cardiol 1981;48:647-654.

6. Saltissi S, Crowther A, Byrne C, Coltart DJ, Jenkins BS, WebbPeploe MM. Assessment of prognostic factors in patients undergoing surgery for non-rheumatic mitral regurgitation. Br Heart J 1980;44:369-380.

7. Crawford MH, Souchek J, Oprian CA, Miller DC, Rahimtoola S, Giacomini JC, Sethi G, Hammermeister KE. Determinants of survival and left venticular performance after mitral valve replacement. Circulation 1990;81:1173-1181.

8. Starling MR, Kirsh MM, Montgomery DG, Gross MD. Mechanisms of left ventricular dilation and dysfunction in aortic regurgitation: importance for establishing the response to aortic valve replacement. J Am Coll Cardiol 1991;17:887-897.

9. Karliner JS, Bouchard RJ, Gault JH. Hemodynamic effects of angiographic contrast material in man. Br Heart J 1972;34:347352.

10. Starling MR, Walsh RA. Accuracy of biplane axial oblique cineangiographic left ventricular cast volume determinations using a modification of Simpson's rule algorithm. Am Heart J 1985;110:1219-1225.

11. Rackley CE, Dodge HT, Coble YD, Hay RE. A method for determining left ventricular mass in man. Circulation 1964;19: $666-671$.

12. Hugenholtz PG, Kaplan E, Hull E. Determination of left ventricular wall thickness by angiocardiography. Am Heart J 1969;78: 513-521. 
13. Mirsky I. Left ventricular stresses in the intact human heart. Biophysiol J 1969;9:189-194.

14. Carabello BA, Spann JF. The uses and limitations of end-systolic indexes of left ventricular function. Circulation 1984;69:10581064.

15. Nakano K, Sugawara M, Ishihara K, Kanazawa S, Corin WJ, Denslow S. Myocardial stiffness derived from end-systolic wall stress and logarithm of reciprocal of wall thickness: contractility index independent of ventricular size. Circulation 1990;82:1352-1361.

16. Nakano K, Swindle M, Spinale F, Ishihara K, Kanazawa S, Smith A. Depressed contractile function due to canine mitral regurgitation improves after correction of the volume overload. J Clin Invest 1991;87:2153-2161.

17. Carabello BA, Nolan SP, McGuire LB. Assessment of preoperative left ventricular function in patients with mitral regurgitation: value of the end-systolic wall stress-end-systolic volume ratio. Circulation 1981;64:1212-1217.

18. Starling MR, Kirsh MM, Montgomery DG, Gross MD. Impaired left ventricular contractile function in patients with long-term mitral regurgitation and normal ejection fraction. J Am Coll Cardiol 1993;22:239-250.

19. Schuler G, Peterson KL, Johnson A, Francis G, Dennish G, Utley J. Temporal response of left ventricular performance to mitral valve surgery. Circulation 1979;59:1218-1231.

20. Nakano S, Sakai K, Taniguchi K, Miyamoto Y, Shintani H, Shimazaki Y. Relation of impaired left ventricular function in mitral regurgitation to left ventricular contractile state after mitral valve replacement. Am J Cardiol 1994;73:70-74.

21. Borow DM, Green LH, Mann T, Sloss LJ, Braunwald E, Collins
JJ. End-systolic volume as a predictor of postoperative left ventricular performance in volume overload from valvular regurgitation. Am J Med 1980;68:655-663.

22. Mudge GH. Asymptomatic mitral regurgitation: when to operate? J Card Surg 1994;9:248-251.

23. Haque ME, Sasaki S, Miyakoda H, Ishiguro S, Kinugawa T, Mori T. Determinants of subsequent late postoperative left ventricular function and reversal of ventricular dilatation after mitral valve replacement for chronic mitral regurgitation. Jpn Heart J 1992;33: 605-618.

24. Zile MR, Gaasch WH, Carroll JD, Levine HJ. Chronic mitral regurgitation: predictive value of preoperative echocardiographic indexes of left ventricular function and wall stress. J Am Coll Cardiol 1984;3:235-242

25. Wisenbaugh T. Mitral valve disease. Curr Opin Cardiol 1994;9: $146-151$

26. Enriquez-Sarano M, Tajik J, Schaff HV, Orszulak TA, McGoon MD, Bailey KR. Echocardiographic prediction of left ventricular function after correction of mitral regurgitation: results and clinical implications. J Am Coll Cardiol 1994;24:1536-1543.

27. Yun KL, Rayhill SC, Niczporuk MA, Fann JI, Derby GC, Daughters GT. Left ventricular mechanics and energetics in the dilated canine heart: acute versus chronic mitral regurgitation. J Thorac Cardiovasc Surg 1992;104:26-39.

28. Nakazawa M, Yasukouchi S, Seguchi M, Oyama K, Momma K, Hosoda S. Combined assessment with myocardial contractility and an index related to ventricular afterload in patients with isolated severe mitral regurgitation undergoing valve replacement. Jpn Heart J 1993;34:201-211. 